\title{
Growth hormone and hematopoiesis: A retrospective analysis on a large cohort of children with growth hormone deficiency
}

\author{
Alessandro Ciresi, Giulia Piazza, Stefano Radellini, Valentina Guarnotta, Maria Grazia Mineo, \\ Carla Giordano*
}

Section of Endocrinology, Biomedical Department of Internal and Specialist Medicine (DIBIMIS), University of Palermo, Italy

\section{A R T I C L E I N F O}

\section{Keywords:}

Growth hormone

Growth hormone deficiency

Children

Growth hormone treatment

Anemia

Hematopoiesis

\begin{abstract}
A B S T R A C T
Objective: Few large-scale studies regarding the impact of GH deficiency (GHD) on hematopoiesis in children have been reported. Our aim was to investigate hematopoiesis indices in a large cohort of GHD children at diagnosis and during GH treatment (GHT) and any correlation with hormonal parameters.

Design: Clinical and biochemical data of children with idiopathic GHD at diagnosis and annually up to 36 months of GHT were retrospectively evaluated. Overall, 255 children reached 12 months, 140 children 24 months and 86 children 36 months of follow-up during GHT.

Results: At baseline, 18.4\% of GHD children and 10.1\% of controls showed normocytic anemia. GHD children showed lower hemoglobin $(\mathrm{Hb})(\mathrm{p}=0.007)$, red blood cells $(\mathrm{RBC})(\mathrm{p}<0.001)$ and hematocrit $(\mathrm{Ht})(\mathrm{p}=0.001)$ than controls. During GHT, the percentage of anemic patients decreased from 18.4 to 5.4-3.5 and $4.6 \%$ after 12 ( $p=0.001), 24(p<0.001)$ and 36 months ( $<<0.001)$ of GHT, respectively. In both anemic and non-anemic patients, a significant increase in $\mathrm{Hb}(\mathrm{p}<0.001,<0.001$ and 0.002), RBC (all $\mathrm{p}<0.001$ ) and Ht (all $\mathrm{p}<0.001$ ) was found after 12, 24 and 36 months of GHT. The Hb levels were significantly correlated with the GH peak after stimulation test $(\mathrm{p}<0.001)$ at baseline and with IGF-I levels at 36 months of GHT $(\mathrm{p}=0.002)$. Conclusions: A significant improvement in erythropoiesis indices occurs during GHT, regardless of any previous presence of anemia.
\end{abstract}

\section{Introduction}

The role of the growth hormone (GH)-insulin like growth factor-I (IGF-I) axis in the regulation of hematopoiesis has widely been recognized [1-4]. Both GH and IGF-I boost the growth of erythroid precursor cells formed by bone marrow and peripheral blood erythroid cells in the presence of erythropoietin (Epo) in vitro [5-8]. Similarly, hypopituitary rats suffer from anemia and have low Epo levels, which can be restored by GH treatment (GHT) and IGF-I [1, 9].

Although there are $\mathrm{GH}$ receptors in the bone marrow, erythrocytes have receptors for IGF-I and it has been hypothesized that the effect of GH is mainly mediated by IGF-I, which has Epo-like activity and can act both directly via an Epo-independent pathway and through enhanced production of Epo $[1,10,11]$. Indeed, in addition to Epo, IGF-I has been demonstrated to stimulate erythropoiesis both in vitro and in vivo
[12-16] and a positive correlation between serum IGF-I levels and $\mathrm{Hb}$ concentration has been shown in healthy children in some studies [17]. However, conflicting data regarding the impact of GH deficiency (GHD) on hematopoiesis in humans have been reported. Some studies document a substantial percentage of anemic patients, ranging from 12 up to $23 \%$, among GHD subjects [2, 18-20], although these data are not confirmed by other authors [4-21].

Discordant data also come from studies on the effect of GHT on hematopoiesis and few large-scale studies or ones with a long follow-up have been reported in children. The effect of GHT on hematopoietic progenitor cells [4-22], as well as on erythropoiesis indices in both adults [21, 23] and children affected by GHD [2, 20, 24, 25] has been documented. However, some studies document a significant impact of GHT on erythropoiesis indices exclusively in patients with anemia and not in the totality of patients [19].

\footnotetext{
Abbreviations: GH, growth hormone; GHT, growth hormone treatment; GHD, growth hormone deficiency; IGF-I, insulin like growth factor-I; Hb, hemoglobin; RBC,

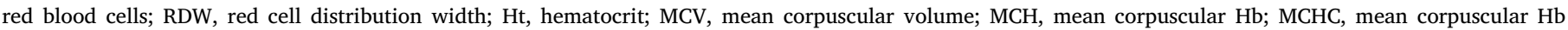
concentration; WBC, white blood cells; PLT, platelets.

* Corresponding author at: Section of Endocrinology, Biomedical Department of Internal and Specialist Medicine (DIBIMIS), University of Palermo, Piazza delle Cliniche 2, 90127 Palermo, Italy.

E-mail address: carla.giordano@unipa.it (C. Giordano).
} 
The current study aimed to investigate hematopoiesis indices in a large homogeneous cohort of GHD children at diagnosis and during GHT and any correlation with clinical and hormonal parameters.

\section{Materials and methods}

We retrospectively evaluated data of 255 children (185 males, 70 females, mean age $8 \pm 1.4$ years; range 3.7-10.9) affected by idiopathic GHD who were consecutively admitted to the Section of Endocrinology of the University of Palermo from January 2005 to January 2018 and underwent GHT for at least 12 consecutive months. Data of 59 healthy children, who were relatives of the patients or who were referred to our Section for short stature or thyroid screening, matched for gender (41 males, 18 females), age (mean age $8 \pm 1.6$ years; range $3.4-10.8$ ), stature and pubertal status were recruited as a control group at baseline. Among these children, nobody showed GHD, impaired thyroid function or other endocrine-metabolic causes of short stature, for which they have been classified as affected by familial short stature or constitutional growth delay. Six children in the control group showed anemia secondary to nutritional causes, after excluding a condition of chronic malabsorption. Ferritin levels resulted however in the normal range in all GHD children and controls at baseline.

Children with organic GHD or multiple pituitary hormone deficiency or receiving other hormonal replacement treatment were excluded from the study, in order to avoid interference with the parameters evaluated. In addition, recognized causes of anemia, such as hypothyroidism, celiac disease, chronic renal failure, iron deficiency or a previous history of cranial irradiation were ruled out, as well as children with already known thalassemic trait and/or hemoglobinopathy or on medications known to affect hematopoiesis, were excluded from this analysis. In this view, we did not treat the few children with anemia during the follow-up because anemia has always been of mild, and never severe, degree.

All children, including the older ones, at baseline were in the first stage of sexual development (girls with Tanner breast stage B1; boys with testicular volume $<4 \mathrm{ml}$ ).

GHD was diagnosed according to the auxological, radiological and biochemical criteria of the GH Research Society [26]. As auxological data we considered height and growth velocity 1 year before diagnosis. As radiological criteria we considered a bone age delay, estimated from an X-ray of the left wrist and hand and evaluated according to the methods of Greulich and Pyle, of at least 1 year with respect to the chronological age [27]. Subsequently, we calculated the bone/chronological age ratio. As per internal protocol, GHD was biochemically diagnosed by failure of GH to respond to the glucagon stimulation test (GST) as a first test and to the insulin tolerance test (ITT) or arginine test (ARG) based on availability, with GH peaks below $10 \mu \mathrm{g} / \mathrm{l}$ until 2015 and below $8 \mu \mathrm{g} / 1$ thereafter, according to the Italian criteria of appropriateness of use and reimbursement of GHT in children [28].

All GHD children received GH once daily at bedtime with a pen injection system. During the entire follow-up, IGF-I levels and growth velocity allowed us to determine the GH dose. Specifically, the main targets were arbitrarily IGF-I levels between $-0.5 /+0.5$ SD and/or growth velocity $\geq 1 \mathrm{SD}$.

On average, in all patients, the initial daily dose of GH was $0.025 \mathrm{mg} / \mathrm{Kg}$. It was gradually increased to $0.027-0.028 \mathrm{mg} / \mathrm{Kg}$ from month 6 to 12 , to $0.029-0.030 \mathrm{mg} / \mathrm{Kg}$ from month 12 to 18 , to $0.030-0.032 \mathrm{mg} / \mathrm{Kg}$ from month 18 to 24 and to $0.032-0.034 \mathrm{mg} / \mathrm{Kg}$ thereafter until 36 months, in order to achieve the above-mentioned targets.

Overall, 255 GHD children reached 12 months, 140 children reached 24 months and 86 children reached 36 months of follow-up during GHT.

\subsection{Study protocol}

In all children at baseline we measured body height (expressed as Standard Deviation, SD) and body mass index (BMI) SD. GH secretion was evaluated by GH levels during GST, ITT or ARG test, performed on different days. During the baseline sampling of one of the two tests, a blood sample was drawn for a full blood count. Evaluation of hemoglobin ( $\mathrm{Hb}$ ) concentration, red blood cells (RBC), hematocrit (Ht), mean corpuscular volume (MCV), mean corpuscular $\mathrm{Hb}(\mathrm{MCH})$ and mean corpuscular $\mathrm{Hb}$ concentration (MCHC) was performed at baseline and annually during the follow-up of GHT. Using age-adjusted normal ranges, $\mathrm{Hb}$ and $\mathrm{RBC}$ were expressed as both absolute and $\mathrm{SD}$ values. Anemia was defined by blood $\mathrm{Hb}$ concentration $<2$ SD below the mean normal values for age [29].

After the diagnosis of GHD was made, in GHD children in addition to auxological parameters and IGF-I measurement we performed a blood count annually, while in the control group these evaluations were only performed at baseline.

The institutional Ethics Committee of the University of Palermo approved this study. At the time of hospitalization, an informed consent for scientific use of the data was obtained from both the participants and their parents.

The data analysis was performed both in the whole group of GHD children and also separately in children with or without anemia at baseline.

\subsection{Hormone and biochemical assays}

The complete blood cell count was performed in the centralized accredited laboratories of the University of Palermo with the standard methods. During the study period GH levels were assayed by immunoradiometric (Radim, Pomezia, Italy) until 2015 and electrochemiluminescence assays (ECLIA, Elecsys hGH, Roche, Milan, Italy) thereafter, according with different availability, with an assay sensitivity of 0.05 and $0.03 \mu \mathrm{g} / 1$, respectively. The intra-assay coefficients of variation (CVs) were $2.5-3.9 \%$ and $0.6-5.0 \%$, respectively and the inter-assay CVs were $3.8-5.0 \%$ for both. Serum total IGF-I was assayed with the ELISA method (OCTEIA IGF-I kit, IDS Inc., Fountain Hills, AZ, USA) until 2013 and by chemiluminescent immunometric assay (Immulite 2000; Diagnostic Products Corp., Los Angeles, CA) using murine monoclonal anti-IGF-I antibodies thereafter. The sensitivity of methods was $1.9 \mu \mathrm{g} / \mathrm{l}$. The standards were calibrated against the World Health Organization second IS $87 / 518$. The intra-assay CVs were $2.3-3.5 \%$ and $2.3-3.9 \%$, respectively and the inter-assay CVs were $7-7.1 \%$ and $3.7-8.1 \%$, respectively.

\subsection{Statistical analysis}

The Statistical Packages for Social Sciences SPSS version 19 was used for data analysis. Baseline characteristics were presented as mean \pm SD for continuous variables (normality of distribution for the quantitative variables was assessed with the Kolmogorov-Smirnov test), rates and proportions were calculated for categorical data. Differences between the 2 independent groups (GHD children and controls) were assessed by Student's test or the Mann-Whitney $U$ test when appropriate, while the differences between paired continuous variables (before and during GHT) were analyzed by the paired Student's $t$-test or the Wilcoxon test, when appropriate. The Spearman rank order correlation test was used to evaluate the relationship between the Hb levels and hormonal parameters. A p value $<0.05$ was considered statistically significant.

\section{Results}

The clinical and biochemical features of control subjects and GHD children at diagnosis are shown in Table 1. 
Table 1

Baseline clinical and biochemical features of GHD children and control subjects. GHD children No Controls No 59 255

\begin{tabular}{|c|c|c|c|}
\hline \multicolumn{3}{|l|}{ Gender } & \multirow[t]{3}{*}{0.373} \\
\hline Males & $185(72.5)$ & $41(69.5)$ & \\
\hline Females & $70(27.5)$ & $18(30.5)$ & \\
\hline & Mean \pm SD & Mean \pm SD & \\
\hline Age (years) & $8 \pm 1.4$ & $8 \pm 1.6$ & 0.823 \\
\hline Height (SD) & $-2.1 \pm 0.5$ & $-2.2 \pm 0.6$ & 0.596 \\
\hline BMI (SD) & $-0.6 \pm 0.4$ & $-1.3 \pm 0.7$ & $<0.001$ \\
\hline Growth velocity (SD) & $-2.3 \pm 0.5$ & $-1.3 \pm 0.8$ & $<0.001$ \\
\hline $\begin{array}{l}\text { Ratio bone/chronological } \\
\text { age }\end{array}$ & $0.81 \pm 0.11$ & $0.87 \pm 1.12$ & $<0.001$ \\
\hline GH peak after GST $(\mu g / l)$ & $3.6 \pm 2.9$ & $11.4 \pm 6.6$ & $<0.001$ \\
\hline $\begin{array}{l}\text { GH peak after ARG or ITT } \\
(\mu \mathrm{g} / \mathrm{l})\end{array}$ & $6.2 \pm 4.5$ & $14.3 \pm 7.4$ & $<0.001$ \\
\hline IGF-I (SD) & $-0.7 \pm 0.6$ & $-0.4 \pm 0.6$ & $<0.001$ \\
\hline Prevalence of anemia & $\begin{array}{l}\text { Subjects (\%) } \\
47(18.4)\end{array}$ & $\begin{array}{l}\text { Subjects (\%) } \\
6(10.1)\end{array}$ & 0.087 \\
\hline & Mean \pm SD & Mean \pm SD & \\
\hline $\mathrm{Hb}(\mathrm{g} / \mathrm{dl})$ & $12.2 \pm 0.9$ & $12.6 \pm 1.1$ & 0.007 \\
\hline $\mathrm{Hb}$ SD & $-0.5 \pm 1$ & $-0.1 \pm 0.7$ & 0.007 \\
\hline $\mathrm{RBC}\left(\times 10^{6} / \mathrm{ml}\right)$ & $4.5 \pm 0.3$ & $4.7 \pm 0.4$ & $<0.001$ \\
\hline RBC SD & $-0.4 \pm 0.6$ & $-0.07 \pm 0.7$ & $<0.001$ \\
\hline RDW\% & $12.9 \pm 0.5$ & $12.9 \pm 0.5$ & 0.971 \\
\hline Ht $(\%)$ & $36.8 \pm 2.4$ & $38.5 \pm 2.1$ & 0.001 \\
\hline MCV (fl) & $82.1 \pm 1.3$ & $81.9 \pm 3.9$ & 0.791 \\
\hline $\mathrm{MCH}(\mathrm{pg})$ & $27.4 \pm 1.2$ & $27.4 \pm 1.2$ & 0.892 \\
\hline $\mathrm{MCHC}(\mathrm{g} / \mathrm{dl})$ & $34.1 \pm 0.4$ & $33.4 \pm 1.3$ & 0.063 \\
\hline WBC $\left(\times 10^{3} / \mathrm{ml}\right)$ & $6.4 \pm 1.3$ & $6.3 \pm 1.4$ & 0.789 \\
\hline PLT $\left(\times 10^{3} / \mathrm{ml}\right)$ & $292 \pm 65$ & $294 \pm 62$ & 0.830 \\
\hline
\end{tabular}

SD: standard deviation; GST: glucagon stimulation test; ARG: arginine stimulation test; Hb: hemoglobin; RBC: red blood cells; RDW: red cell distribution width; Ht: hematocrit; MCV: mean corpuscular volume; $\mathrm{MCH}$ : mean corpuscular Hb; MCHC: mean corpuscular Hb concentration; WBC: white blood cells; PLT: platelets.

At baseline, GHD children showed significantly lower growth velocity ( $\mathrm{p}<0.001$ ), bone/chronological age ratio ( $\mathrm{p}<0.001$ ), IGF-I ( $\mathrm{p}<0.001$ ), GH peak after stimulation tests (all $\mathrm{p}<0.001$ ) and GH peak after arginine test $(\mathrm{p}<0.001)$, and higher BMI $(\mathrm{p}<0.001)$ than control subjects, while no significant difference in height between GHD children and controls was found.

The percentage of anemic patients was $18.4 \%$ (47 children) in the GHD group and $10.1 \%$ ( 6 children) in the control group $(\mathrm{p}=0.087)$. GHD children showed lower Hb $(\mathrm{p}=0.007)$, RBC $(\mathrm{p}<0.001)$ and Ht $(\mathrm{p}=0.001)$, while no difference was found in other hematopoietic parameters.

The clinical and biochemical features of GHD children during GHT are shown in Table 2.

In GHD children we observed a significant increase in height (all $\mathrm{p}<0.001$ ), growth velocity (all $\mathrm{p}<0.001$ ) and IGF-I (all $\mathrm{p}<0.001$ ) after 12, 24 and 36 month of GHT, while no difference was found in BMI.

The percentage of anemic patients decreased from $18.4 \%$ at baseline to $5.4 \%, 3.5 \%$ and $4.6 \%$ after $12(\mathrm{p}=0.001), 24(\mathrm{p}<0.001)$ and 36 months ( $p<0.001)$ of GHT, respectively.

A significant increase in $\mathrm{Hb}(\mathrm{p}<0.001,<0.001$ and 0.002$)$, RBC (all $\mathrm{p}<0.001$ ), Ht (all $\mathrm{p}<0.001$ ), and decrease in MCV (all $\mathrm{p}<0.001)$ and MCHC ( $\mathrm{p}=0.021,<0.001$ and 0.002$)$ was found after 12, 24 and 36 months of GHT, respectively, while MCH decreased after $24(\mathrm{p}=0.001)$ and 36 months $(\mathrm{p}=0.003)$. No significant change was found in RDW, WBC and PLT values.

When we separately analyzed the hematopoietic parameters in GHD children according to the presence of anemia at baseline, both in anemic and non-anemic patients we confirmed the same significant changes shown for the whole group (data not shown).
In GHD children, the $\mathrm{Hb}$ levels were significantly correlated with the GH peak after stimulation test (Rho 0.428, p < 0.001) and not with IGF-I ( $p=0.254)$ at baseline, and with IGF-I levels at 36 months of GHT (Rho 0.336, $\mathrm{p}=0.002$ ) (Fig. 1).

\section{Discussion}

In this study we found that children with GHD show a higher prevalence of anemia than controls and GHT leads to a significant improvement in hematopoietic indices.

The evidence of the close relationship between GH-IGF-I axis and hematopoiesis comes from studies on children with congenital anemia [30]. To confirm this, several studies document some degree of anemia, mainly characterized by lower $\mathrm{Hb}$ and RBC, in GHD patients compared to controls [21, 25], although other studies did not show significant abnormality in peripheral RBC in GHD patients at diagnosis [4, 21].

In the current study we demonstrated that GHD children at diagnosis have significantly lower levels of $\mathrm{Hb}, \mathrm{RBC}$ and $\mathrm{Ht}$, with a prevalence of about $18 \%$ of anemia, higher than that highlighted in healthy controls. These data are wholly in agreement with those of previous studies. Indeed, in 2002 Eugster et al. documented an incidence of $12 \%$ of overt normochromic normocytic anemia among 100 children with GHD [18], while higher percentages (from 14 up to 23\%) were found by other authors $[2,19,20]$.

The impact of GHT on hematopoiesis has been quite debated. In our study, in addition to the expected improvement in clinical and auxological parameters, we found a significant decrease in the percentage of anemic patients during GHT, with a significant increase in $\mathrm{Hb}$ and RBC levels. The increase occurred mainly after 12 months of GHT and subsequently stabilized, always remaining within the normal values.

GHT has proven to have a marked effect on erythroid progenitor precursors, but negligible effects on peripheral blood cells. Indeed, a significant impact of GH on hematopoietic progenitor cells was documented in 40 GHD children after 3 and 6 months of GHT [22]. Similarly, Kotzmann et al. showed that 11 adult patients had hematopoietic precursor cells in the lower normal range. In addition, the authors demonstrated a significant increase in erythroid progenitor precursor cells after 24 months of GHT, whereas the parameters reflecting erythropoiesis in the peripheral blood, such as reticulocytes and RBC, exhibited only minimal and non-significant changes [4].

Conversely, in 1993 Ardizzi et al. showed a significant increase in number of RBC, $\mathrm{Hb}$ and Ht values in 8 subjects with GHD after 9 months of GHT and they concluded that GH would also appear to stimulate erythropoiesis in vivo [31] and these data are in agreement with our study. Similar data were previously demonstrated both in adults and children with GHD. Ten Have et al. showed a significant increase in $\mathrm{Hb}$ levels from week 36 and up to 120 weeks of GHT in a group of 17 GHD adults [23], while Christ et al. demonstrated a stimulatory effect of GHT on RBC in 13 adults with GHD [21].

Similar results come from pediatric populations. Indeed, the positive effect of GHT on hematopoiesis has been demonstrated by Vihervuori et al. in 36 GHD children during the first 6 months of GHT [24] and by Valerio et al. who analyzed the erytropoiesis indices of 19 GHD children, confirming the in vivo erytropoietic growth-promoting effects of $\mathrm{GH}$, as demonstrated by the increase in $\mathrm{Hb}, \mathrm{Ht}$ and $\mathrm{RBC}$ values after 6 months of GHT [25]. More recently, Miniero et al. confirmed the positive impact of GHT in a large series of 279 GHD children retrospectively evaluated after 48 months of treatment [20]. In agreement with these data, the long-term effects of GHT on erythrocytes parameters were shown by Esposito et al. who evaluated 85 GHD children during the first 5 years of treatment and documented a significant increase in $\mathrm{Hb}, \mathrm{Ht}$ and $\mathrm{RBC}$ which became comparable to controls within the first 2 years [2].

However, some studies only document a positive impact of GHT on hemopoietic indices only in already anemic GHD patients. Bergamaschi et al. documented that, when a condition of normochromic normocytic 
Table 2

Clinical and biochemical features at baseline and during GH treatment (GHT) of GHD children.

\begin{tabular}{|c|c|c|c|c|c|c|c|}
\hline & Baseline No 255 & 12 months No 255 & 24 months No 140 & 36 months No 86 & $\mathrm{p}$ & $\mathrm{p}^{*}$ & $\mathrm{p}^{* * *}$ \\
\hline & Mean $\pm S D$ & Mean \pm SD & Mean $\pm S D$ & Mean \pm SD & & & \\
\hline Height (SD) & $-2.1 \pm 0.5$ & $-1.7 \pm 0.5$ & $-1.3 \pm 0.5$ & $-1.1 \pm 0.5$ & $<0.001$ & $<0.001$ & $<0.001$ \\
\hline BMI (SD) & $-0.6 \pm 0.4$ & $-0.7 \pm 0.7$ & $-0.6 \pm 0.7$ & $-0.6 \pm 0.5$ & 0.272 & 0.241 & 0.245 \\
\hline Growth velocity (SD) & $-2.3 \pm 0.5$ & $-1 \pm 0.6$ & $-0.2 \pm 0.3$ & $-0.4 \pm 0.5$ & $<0.001$ & $<0.001$ & $<0.001$ \\
\hline \multirow[t]{2}{*}{ IGF-I (SD) } & $-0.7 \pm 0.6$ & $-0.1 \pm 0.4$ & $0.1 \pm 0.2$ & $0.2 \pm 0.3$ & $<0.001$ & $<0.001$ & $<0.001$ \\
\hline & Subjects (\%) & Subjects (\%) & Subjects (\%) & Subjects (\%) & & & \\
\hline \multirow[t]{2}{*}{ Prevalence of anemia } & $47(18.4)$ & $14(5.4)$ & $5(3.5)$ & $4(4.6)$ & 0.001 & $<0.001$ & $<0.001$ \\
\hline & Mean $\pm S D$ & Mean \pm SD & Mean $\pm S D$ & Mean $\pm S D$ & & & \\
\hline $\mathrm{Hb}(\mathrm{g} / \mathrm{dl})$ & $12.2 \pm 0.9$ & $13.1 \pm 1.1$ & $13.2 \pm 0.5$ & $13.3 \pm 0.9$ & $<0.001$ & $<0.001$ & 0.002 \\
\hline $\mathrm{Hb}$ SD & $-0.5 \pm 1$ & $0.02 \pm 0.7$ & $0.1 \pm 0.6$ & $0.09 \pm 0.6$ & $<0.001$ & $<0.001$ & $<0.001$ \\
\hline $\mathrm{RBC}\left(\times 10^{6} / \mathrm{ml}\right)$ & $4.5 \pm 0.3$ & $4.9 \pm 0.5$ & $4.8 \pm 0.6$ & $4.8 \pm 0.6$ & $<0.001$ & $<0.001$ & $<0.001$ \\
\hline $\mathrm{RBC} S \mathrm{D}$ & $-0.4 \pm 0.6$ & $-0.01 \pm 0.9$ & $0.02 \pm 0.9$ & $0.01 \pm 0.9$ & $<0.001$ & $<0.001$ & $<0.001$ \\
\hline RDW\% & $12.9 \pm 0.5$ & $12.9 \pm 0.4$ & $13 \pm 0.3$ & $13 \pm 0.4$ & 0.656 & 0.365 & 0.597 \\
\hline Ht (\%) & $36.8 \pm 2.4$ & $38.7 \pm 3.8$ & $39.5 \pm 2.5$ & $39.6 \pm 3.9$ & $<0.001$ & $<0.001$ & $<0.001$ \\
\hline $\operatorname{MCV}(\mathrm{fl})$ & $82.1 \pm 1.3$ & $79.6 \pm 2$ & $79.2 \pm 1.8$ & $78.7 \pm 1.7$ & $<0.001$ & $<0.001$ & $<0.001$ \\
\hline MCH (pg) & $27.4 \pm 1.2$ & $27.2 \pm 1.4$ & $26.2 \pm 1.3$ & $25.8 \pm 1.5$ & 0.513 & 0.001 & 0.003 \\
\hline $\mathrm{MCHC}(\mathrm{g} / \mathrm{dl})$ & $34.1 \pm 0.4$ & $33.4 \pm 1.1$ & $32.9 \pm 0.8$ & $33.1 \pm 1.1$ & 0.021 & $<0.001$ & 0.002 \\
\hline $\mathrm{WBC}\left(\times 10^{3} / \mathrm{ml}\right)$ & $6.4 \pm 1.3$ & $6.4 \pm 1.4$ & $6.3 \pm 1.2$ & $6.3 \pm 1.2$ & 0.871 & 0.157 & 0.130 \\
\hline $\operatorname{PLT}\left(\times 10^{3} / \mathrm{ml}\right)$ & $292 \pm 65$ & $288 \pm 59$ & $300 \pm 56$ & $293 \pm 50$ & 0.203 & 0.949 & 0.330 \\
\hline
\end{tabular}

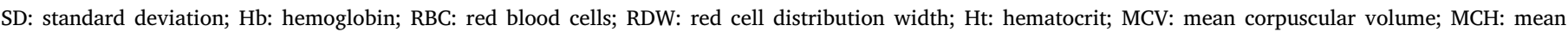
corpuscular Hb; MCHC: mean corpuscular Hb concentration; WBC: white blood cells; PLT: platelets.

$\mathrm{p}$ : difference between values at 12 months and baseline.

$\mathrm{p}^{*}$ : difference between values at 24 months and baseline.

$\mathrm{p}^{* * *}$ : difference between values at 36 months and baseline.
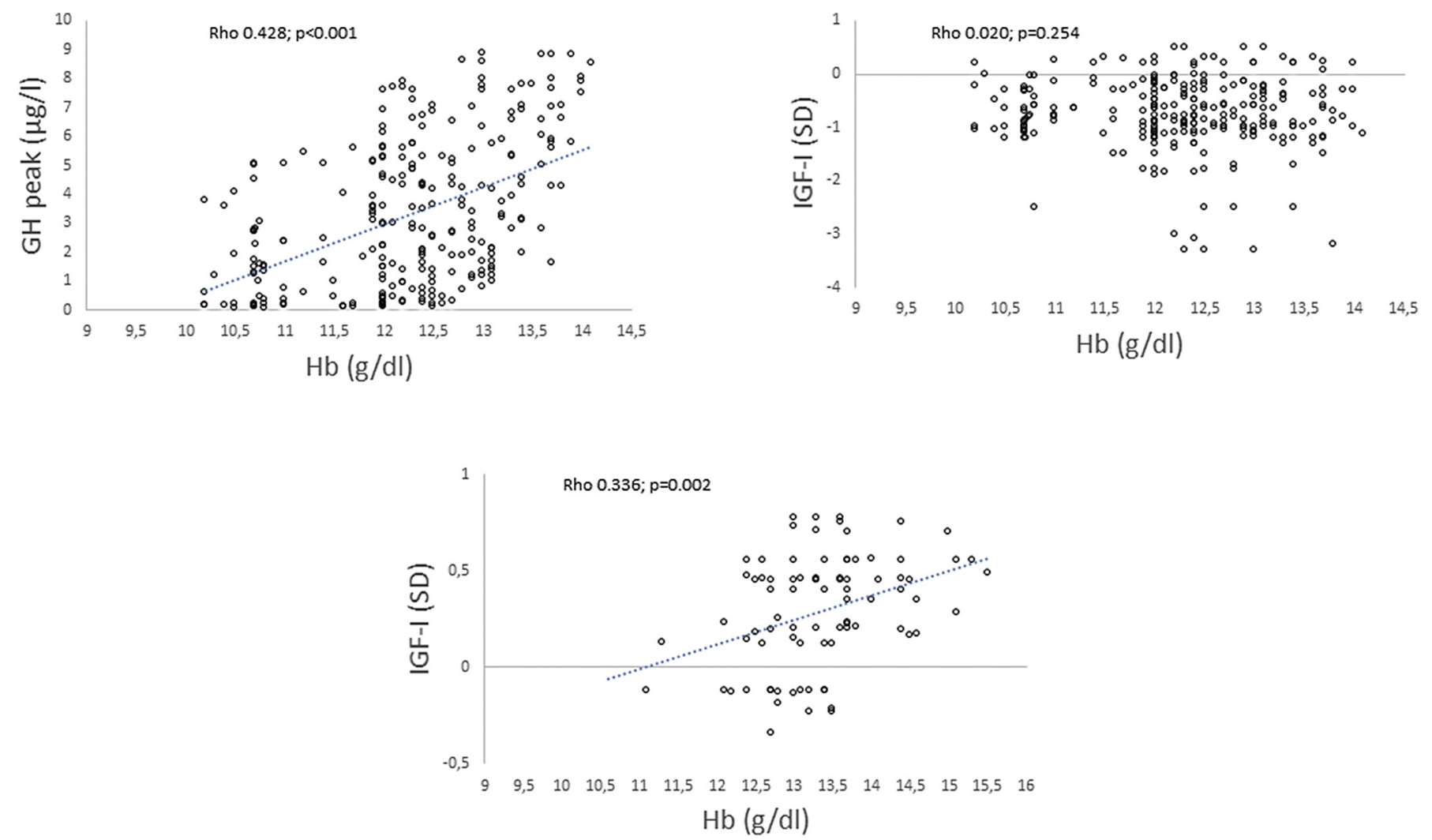

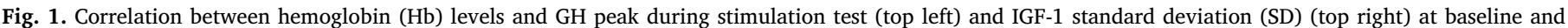
between Hb levels and IGF-1 SD at 36 months of GH treatment (bottom).

anemia was present, GHT was able to restore normal Hb levels in GHD patients, while no effect in patients with baseline normal indices was found [19]. Similarly, Esposito et al. demonstrated a normalization of $\mathrm{Hb}$ levels in all anemic GHD children after 5 years of GHT [2] and Sohmiya et al. documented similar beneficial effects of GHT in anemic adult patients with GHD [3]. By contrast, in our study we documented a positive effect of GHT both in the whole cohort of GHD children and independently in the anemic and non-anemic group.

Significantly, confirming the role of GH/IGF-I axis in stimulating erythropoiesis in vivo, we found a significant correlation between $\mathrm{Hb}$ 
levels and GH peak during a stimulation test at baseline and with IGF-I levels during GHT. Indeed, it is well known that IGF-I levels are not very useful as a diagnostic tool, especially in children, because a number of factors may affect its measurements and in GHD too values of IGF-I within the normal range can occur, while during GHT they become more useful due to its close GH dependency, although they do not always correlate well with the growth response [26, 32]. A close relationship between the increase in erythropoiesis indices and IGF-I levels has already been demonstrated during GHT both in adults [23] and in children [2, 20,24], although Kotzmann et al. demonstrated that the increase of IGF-I levels during GHT in a group of 11 adult patients was more associated with increased erythroid precursor cells than peripheral RBC [4].

In this study, we cannot exclude or confirm the impact of GHT or IGF-I on Epo secretion, the main regulator of human erythropoiesis, because we did not measure Epo levels. Indeed, an early increase in Epo during the first week of GHT, probably secondary to initial hemodiluition and a decrease in Hb levels, was documented [3, 33] and Quin et al. reported the in vivo stimulatory effect of IGF-I therapy on Epo concentrations [34]. However, no effect of GHT on Epo was found by other studies in both adult $[4,21]$ and pediatric GHD patients [35].

GHT seems to increase all erythropoiesis indices with the exception of MCV [31]. Indeed, all red cell indices, i.e. MCV, MCH and MCHC, were shown to be reduced during GHT by previous studies, probably due to the increased demand for iron secondary to the increased erythrocyte production rate $[21,36]$ and these data are in agreement with our results. In particular, we found comparable MCV, MCH and MCHC at baseline between GHD children and controls, with a significant decrease of these parameters during GHT, although they remained into the normal range.

The effect of GHD or GHT on peripheral red cells could theoretically be explained by the effect of GH on plasma volume. It is known that extracellular water is decreased in untreated GHD [37, 38] and GHT leads it to increase [39]. Indeed, Vihervuori et al. demonstrated that $\mathrm{Hb}$ concentrations fell during the first week of GHT and were accompanied by a consequent increase in Epo secretion, probably due to the initial hemodiluition and fluid-retaining effect of GH [33]. However, in this study we did not evaluate this effect of GHT so we cannot be sure we can exclude this component.

In addition to the well known IGF-I effects on erythropoiesis, the stimulating effect of GH could also be explained by an anabolic effect. Indeed, GH increases the necessity for oxygen transport to peripheral tissues, resulting in increased oxygen transportation and $\mathrm{Hb}$ levels [40].

No significant change in WBC and PLT levels was found in this study. Neither GHD nor GHT seem to influence these parameters, in agreement with previous reports [2,35]. Data about the effect of GHT on WBC and PLT are quite discordant in literature, However, it seems that only neutrophil count increases after GHT, and not lymphocyte, monocyte or eosinophil counts [41], while in our study we just evaluated the total WBC levels. In addition, it must be kept into account the physiological change of WBC and PLT during growth, which could counteract a potential stimulatory effect of GHT, as well as a limit of our study is that we only evaluated the cells count, while we did not perform functional tests of these cells.

This study undoubtedly has some limitations, mainly represented by the lack of follow-up data for the control group. In addition, adding data on Epo levels and iron metabolism during the follow-up will certainly confirm these data in future studies. Conversely, in our opinion the strength of this study is represented by the number and homogeneity of the cohort of patients enrolled and the duration of follow-up.

\section{Conclusions}

This study show that a significant percentage of GHD children have normocytic normochromic anemia and confirm that a significant improvement in erythropoiesis indices occurs during GHT, confirming the in vivo erytropoietic growth-promoting effect of GH regardless of any previous presence of anemia and without significant impact on WBC and PLT. Therefore, a full blood count should always be performed routinely during the follow-up of children with GHD and changes during GHT should be assessed before any further investigation or intervention. However, the exact mechanism through which GH impacts hematological indices remains not fully understood, as well as, in absence of data about potential variations in EPO or iron metabolism during the follow-up, the clear causal role of GHD and GHT remains to be established.

\section{Disclosure statement}

The authors have nothing to disclose.

\section{Grants}

This research did not receive any specific grant from any funding agency in the public, commercial or non-profit sector.

\section{Conflict of interest}

All authors declare that there is no conflict of interest that could be perceived as prejudicing the impartiality of the research reported.

\section{References}

[1] A. Kurtz, J. Zapf, K.U. Eckardt, G. Clemons, E.R. Froesch, C. Bauer, Insulin-like growth factor I stimulates erythropoiesis in hypophysectomized rats, Proc. Natl. Acad. Sci. U. S. A. 85 (1988) 7825-7829.

[2] A. Esposito, D. Capalbo, L. De Martino, M. Rezzuto, R. Di Mase, C. Pignata, M. Salerno, Long-term effects of growth hormone (GH) replacement therapy on hematopoiesis in a large cohort of children with GH deficiency, Endocrine 53 (2016) 192-198.

[3] M. Sohmiya, Y. Kato, Effect of long-term administration of recombinant human growth hormone (rhGH) on plasma erythropoietin (EPO) and haemoglobin levels in anaemic patients with adult GH deficiency, Clin. Endocrinol. 55 (2001) 749-754.

[4] H. Kotzmann, M. Riedl, M. Clodi, U. Barnas, A. Kaider, P. Höcker, A. Luger, The influence of growth hormone substitution therapy on erythroid and myeloid progenitor cells and on peripheral blood cells in adult patients with growth hormone deficiency, Eur. J. Clin. Investig. 26 (1996) 1175-1181.

[5] D.W. Golde, N. Bersch, C.H. Li, Growth hormone: species-specific stimulation of erythropoiesis in vitro, Science 196 (1977) 1112-1113.

[6] M. Claustres, P. Chatelain, C. Sultan, Insulin-like growth factor I stimulates human erythroid colony formation in vitro, J. Clin. Endocrinol. Metab. 65 (1987) 78-82.

[7] S. Merchav, I. Tatarsky, Z. Hochberg, Enhancement of erythropoiesis in vitro by human growth hormone is mediated by insulin-like growth factor I, Br. J. Haematol. 70 (1988) 267-271.

[8] M.B. Hanley, L.A. Napolitano, J.M. McCune, Growth hormone-induced stimulation of multilineage human hematopoiesis, Stem Cells 23 (2005) 1170-1179.

[9] E. Nagy, I. Berczi, Pituitary dependence of bone marrow function, Br. J. Haematol. 71 (1989) 457-462.

[10] C. Polychronakos, H.J. Guyda, B.I. Posner, Receptors for the insulin-like growth factors on human erythrocytes, J. Clin. Endocrinol. Metab. 57 (1983) 436-438.

[11] P.N. Correa, A.A. Axelrad, Production of erythropoietic bursts by progenitor cells from adult human peripheral blood in an improved serum-free medium: role of insulinlike growth factor 1, Blood 78 (1991) 2823-2833.

[12] A. Kurtz, R. Matter, K.U. Eckardt, J. Zapf, Erythropoiesis, serum erythropoietin, and serum IGF-I in rats during accelerated growth, Acta Endocrinol. 122 (1990) 323-328.

[13] S.H. Boyer, T.R. Bishop, O.C. Rogers, A.N. Noyes, L.P. Frelin, S. Hobbs, Roles of erythropoietin, insulin-like growth factor 1 , and unidentified serum factors in promoting maturation of purified murine erythroid colony-forming units, Blood 80 (1992) 2503-2512

[14] K. Muta, S.B. Krantz, M.C. Bondurant, A. Wickrema, Distinct roles of erythropoietin, insulin-like growth factor I, and stem cell factor in the development of erythroid progenitor cells, J. Clin. Invest. 94 (1994) 34-43.

[15] M. Sanders, S. Sorba, N. Dainiak, Insulin-like growth factors stimulate erythropoiesis in serum-substituted umbilical cord blood cultures, Exp. Hematol. 21 (1993) 25-30.

[16] G. Tsarfaty, D.L. Longo, W.J. Murphy, Human insulin-like growth factor I exerts hematopoietic growth-promoting effects after in vivo administration, Exp. Hematol. 22 (1994) 1273-1277.

[17] R. Anttila, R. Koistinen, M. Seppälä, H. Koistinen, M.A. Siimes, Insulin-like growth factor I and insulin-like growth factor binding protein 3 as determinants of blood hemoglobin concentration in healthy subjects, Pediatr. Res. 36 (1994) 745-748.

[18] E.A. Eugster, M. Fisch, E.C. Walvoord, L.A. Dimeglio, O.H. Pescovitz, Low 
hemoglobin levels in children with in idiopathic growth hormone deficiency, Endocrine 18 (2002) 135-136.

[19] S. Bergamaschi, C. Giavoli, E. Ferrante, A. Lania, R. Rusconi, A. Spada, P. BeckPeccoz, Growth hormone replacement therapy in growth hormone deficient children and adults: effects on hemochrome, J. Endocrinol. Investig. 29 (2006) 399-404.

[20] R. Miniero, F. Altomare, M. Rubino, P. Matarazzo, C. Montanari, A. Petri, G. Raiola, G. Bona, Effect of recombinant human growth hormone (rhGH) on hemoglobin concentration in children with idiopathic growth hormone deficiency-related anemia, J. Pediatr. Hematol. Oncol. 34 (2012) 407-411.

[21] E.R. Christ, M.H. Cummings, N.B. Westwood, B.M. Sawyer, T.C. Pearson, P.H. Sönksen, D.L. Russell-Jones, The importance of growth hormone in the regulation of erythropoiesis, red cell mass, and plasma volume in adults with growth hormone deficiency, J. Clin. Endocrinol. Metab. 82 (1997) (2985-2890).

[22] M.P. Kawa, I. Stecewicz, K. Piecyk, E. Pius-Sadowska, E. Paczkowska, D. Rogińska, A. Sobuś, K. Łuczkowska, E. Gawrych, E. Petriczko, M. Walczak, B. Machaliński, Effects of growth hormone therapeutic supplementation on hematopoietic stem/ progenitor cells in children with growth hormone deficiency: focus on proliferation and differentiation capabilities, Endocrine 50 (2015) 162-175.

[23] S.M. Ten Have, A.J. van der Lely, S.W. Lamberts, Increase in haemoglobin concentrations in growth hormone deficient adults during human recombinant growth hormone replacement therapy, Clin. Endocrinol. 47 (1997) 565-570.

[24] E. Vihervuori, I. Sipilä, M.A. Siimes, Increases in hemoglobin concentration and iron needs in response to growth hormone treatment, J. Pediatr. 125 (1994) $242-245$

[25] G. Valerio, S. Di Maio, M. Salerno, A. Argenziano, R. Badolato, A. Tenore, Assessment of red blood cell indices in growth-hormone-treated children, Horm. Res. 47 (1997) 62-66.

[26] Growth Hormone Research Society, Consensus guidelines for the diagnosis and treatment of growth hormone (GH) deficiency in childhood and adolescence: summary statement of the GH research society, J. Clin. Endocrinol. Metab. 85 (2000) 3990-3993.

[27] W. Greulich, S. Pyle, Radiographic Atlas of Skeletal Development of the Hand and Wrist, second ed., Stanford University Press, Stanford, CA, 1959.

[28] A. Ciresi, F. Cicciò, M.C. Amato, C. Giordano, Revaluation of the clinical and metabolic behavior of children with isolated growth hormone deficiency during $\mathrm{GH}$ treatment according to newly proposed note 39 of the Italian Medicines Agency (AIFA), J. Endocrinol. Investig. 38 (2015) 1301-1307.

[29] P.R. Dallman, M.A. Siimes, Percentile curves for hemoglobin and red cell volume in infancy and childhood, J. Pediatr. 94 (1979) 26-31.

[30] O. Mäkitie, E. Juvonen, L. Dunkel, I. Kaitila, M.A. Siimes, Anemia in children with cartilage-hair hypoplasia is related to body growth and to the insulin-like growth factor system, J. Clin. Endocrinol. Metab. 85 (2000) 563-568.

[31] A. Ardizzi, G. Guzzaloni, G. Grugni, D. Moro, G. Calò, G. Mazzilli, E. Tonelli, F. Morabito, The effect of GH on erythropoiesis in vivo, Minerva Endocrinol. 18 (1993) 83-85.

[32] G. Federico, S. Cianfarani, Usefulness of serum insulin-like growth factor I assessment in the diagnosis of childhood-onset growth hormone deficiency, Horm Res. Paediatr. 74 (2010) 145-148.

[33] E. Vihervuori, M. Virtanen, H. Koistinen, R. Koistinen, M. Seppälä, M.A. Siimes, Hemoglobin level is linked to growth hormone-dependent proteins in short children, Blood 87 (1996) 2075-2081.

[34] J.D. Quin, J.P. Miell, K. Smith, D. Gordon, J. Strachan, J.B. Dick, A.C. MacCuish, Effect of insulin-like growth factor-I therapy on erythropoetin concentrations in extreme insulin resistance, Diabetologia 37 (1994) 439.

[35] C. Meazza, I. Bonomelli, S. Pagani, P. Travaglino, K. Laarej, F. Cantoni, M. Bozzola, Effect of human recombinant growth hormone therapy on circulating levels of erythropoietin and granulocyte-colony stimulating factor in short children, J. Pediatr. Endocrinol. Metab. 22 (2009) 837-843.

[36] M. Pankratova, A. Yusipovich, M. Vorontsova, E. Parshina, S. Bochkareva, A. Cherkashin, A. Baizhumanov, M. Silicheva, T. Shiryaeva, G. Maksimov, V. Peterkova, One-year recombinant growth hormone therapy does not improve hemoglobin state and morphology of erythrocytes in growth hormone deficient children, Pathophysiology 25 (2018) 13-17.

[37] A. Binnerts, P. Deurenberg, G.R. Swart, J.H. Wilson, S.W. Lamberts, Body composition in growth hormone-deficient adults, Am. J. Clin. Nutr. 55 (1992) 918-923.

[38] T. Rosén, I. Bosaeus, J. Tölli, G. Lindstedt, B.A. Bengtsson, Increased body fat mass and decreased extracellular fluid volume in adults with growth hormone deficiency, Clin. Endocrinol. 38 (1993) 63-71.

[39] B.A. Bengtsson, S. Edén, L. Lönn, H. Kvist, A. Stokland, G. Lindstedt, I. Bosaeus, J. Tölli, L. Sjöström, O.G. Isaksson, Treatment of adults with growth hormone (GH) deficiency with recombinant human GH, J. Clin. Endocrinol. Metab. 76 (1993) 309-317.

[40] J.H. Jepson, E.E. McGarry, Hemopoiesis in pituitary dwarfs treated with human growth hormone and testosterone, Blood 39 (1972) 229-248.

[41] M. Sohmiya, I. Kanazawa, Y. Kato, Effect of recombinant human GH on circulating granulocyte colony-stimulating factor and neutrophils in patients with adult GH deficiency, Eur. J. Endocrinol. 152 (2005) 211-215. 